\title{
MODEL FOR ESTIMATING ATMOSPHERIC OZONE CONTENT OVER EUROPE FOR USE IN SOLAR RADIATION ALGORITHMS
}

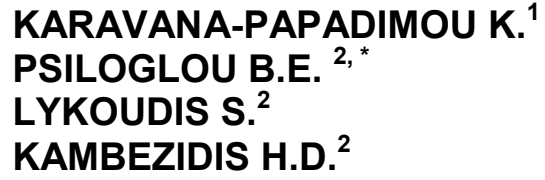

${ }^{1}$ National \& Kapodistrian University of Athens, Department of Geology \& Geo environment, University Campus, 15784 Athens, Greece ${ }^{2}$ Institute for Environmental Research and Sustainable Development, National Observatory of Athens, 15236 Athens, Greece

\begin{abstract}
Part of the attenuation of the incoming solar radiation by the atmosphere is caused by ozone absorption in the UV and visible portions of the spectrum. Ozone absorption typically accounts for only 2-3 $\%$ of the global solar radiation depletion, but it is often $10-20 \%$ of the absorption of the direct component. Thus, broadband solar radiation models require atmospheric ozone content as input in order to correctly calculate the direct component. Van Heuklon in 1979 described the general spatial and temporal characteristics of the ozone column in the atmosphere with an empirical mathematical relationship that can be easily incorporated into solar radiation transmission models (codes). The model requires only the day of the year, the latitude and longitude of the location of interest in order to calculate the total ozone column for that place and time, based upon observed climatological averages. In this study, the validity of van Heuklon's formula for the atmospheric ozone content estimation is tested against satellite measurements for a number of cities in Europe. A new model based on the van Heuklon formula is fitted, with promising results.
\end{abstract}

KEYWORDS: Ozone, Solar radiation, van Heuklon, Total Ozone Mapping Spectrometer (TOMS).

\section{INTRODUCTION}

Solar radiation is absorbed by the lower troposphere and by the Earth's surface and is one of the major driving sources of tropospheric air motion. The prediction of solar radiation at the Earth's surface, using physical meteorological models, requires knowledge of the transmission functions of all atmospheric constituents, and a good estimation of their respective amounts in the atmosphere.

Though water vapor is the principal absorber of solar radiation in the atmosphere, the atmospheric ozone absorption is also of high importance, typically accounting for only $2-3 \%$ of solar radiation's attenuation, especially in the ultraviolet B-region, but its contribution can reach up to 9-10\% especially at high latitudes during summer (Eichmann et al., 2002; Fioletovet et al., 2005). Several methods exist for calculating absorption due to ozone (Lacis and Hansen, 1974; Hoyt, 1978; Bird and Hulstrom, 1981; Psiloglou et al., 1996), but they need the amount of ozone in the optical path as input. Consequently, the determination of ozone absorption relies upon the estimation of the ozone content of the atmosphere at a place and time.

Ozone's variation in the stratosphere is divided into three categories, depending on different factors. There is a variation caused by solar radiation, which varies according to the annual/seasonal variation and to the latitudinal/longitudinal variation. The variation attributed to long-term ozone changes is associated with the declining concentration of ODSs (Ozone Depletion Substances) and with the greenhouse gases' increase. These changes are often relevant with climate behavior (Ray et al., 2010). Also there is a variation attributed to short-term ozone changes which are primarily scientific in nature (related to volcanic eruptions, quasi-biennial oscillation or El Niño-Southern Oscillation) 
and moderate the long-term changes and further more solar radiation, through external effects such as volcanic eruptions, or the 27-day or 11-year cycles in solar variability (Fioletov, 2009).

Before the launch of satellite-born instruments for measuring ozone's total column from space, van Heuklon (1979) introduced a simple mathematical model, in order to represent the general spatial and temporal characteristics of ozone presence in the atmosphere (Kambezidis, 2012). In fact, the van Heuklon model requires only the day of the year and the latitude and longitude of the location of interest to calculate the total ozone column (van Heuklon, 1979). According to the model, the atmospheric amounts of ozone (in Dobson Units) for any day of the year and any location in the Earth's northern hemisphere, is the result of the combination of three variations around the equatorial annual average atmospheric ozone content, $\mathrm{J}$ :

$\mathrm{O}_{3}=\mathrm{J}+\mathrm{A} \cdot \sin ^{2}(\beta \cdot \varphi)+\mathrm{C} \cdot \sin [\mathrm{D} \cdot(\mathrm{E}+\mathrm{F})]\left[\sin ^{2}(\beta \cdot \varphi)\right]+\mathrm{G} \cdot \sin [\mathrm{H}(\lambda+\mathrm{I})]\left[\sin ^{2}(\beta \cdot \varphi)\right]$

where $\varphi$ is latitude (degrees), and $\lambda$ longitude (degrees). According to van Heuklon's model, the parameter $A$ is taken as constant and it represents the part of the ozone increase that can be attributed to latitude effects alone. $\beta$ is also constant (1.28) and is a correction factor for the latitude of maximum ozone content. Parameter $C$ is the half amplitude of the seasonal variation wave. The seasonal variation also depends on $E$ (which is the day of the year), constant $D$ (equal to 0.9856 ), which makes the number of days a fractional part of 360 , and the correction parameter $F$, taken as constant, which transposes the days of maximum and minimum observations accordingly to the maximum and minimum of the variation wave (days 90 and 180 respectively).

$G$ is equivalent to the half amplitude of the maximum observed longitudinal variation. The longitudinal variation also depends on $\mathrm{H}, \mathrm{I}, \beta$ and longitude and latitude as well. I is added empirically to modify the longitude and $\mathrm{H}$ corrects this total resulting in the repetition of the sine wave every $120^{\circ}$.

The squared sine is used rather than the simple sine to produce the broad minimum of low latitudes and strongest gradients in the mid-latitudes in accordance to the observed spatial distribution. Therefore, eq. (1) becomes for the European area:

$\mathrm{O}_{3}=235+\left\{150+40 \cdot \sin [0.9865 \cdot(\mathrm{E}-30)]+20 \cdot \sin [(3 \cdot(\lambda+20)]\} \cdot\left[\sin ^{2}(1.28 \cdot \varphi)\right]\right.$

Satellite measurements of atmospheric ozone in the last decades report an average atmospheric ozone amount of 300-400 D.U., reaching a minimum at equatorial latitudes and increasing polewards, in both hemispheres, to a maximum of 400 D.U.at the sub polar latitudes. Over the tropics the ozone vertical distribution is generally constant throughout the year, but at higher latitudes a marked seasonal variation is observed.

In order to understand the spatial and seasonal ozone's distribution, it is of high importance to use a set of measurements extending over decades, providing spatial and temporal coverage, as well as high quality of measurements. Such programs have been organized under the auspices of the Stratospheric Processes And their Role in Climate (SPARC), the International Ozone Commission (IOC), the Integrated Global Atmospheric Chemistry Observations $\left(\right.$ IGACO-O $\left.{ }_{3}\right)$ and the Network for the Detection of Atmospheric Composition Change (NDACC). High quality total ozone measurements are taken by several systems, stable to $\sim 1 \%$ per decade, all showing the same regional patterns in total ozone evolution over the last 30 years, most notably the lack of a long-term trend in the tropics and different evolutions of total ozone in the Northern and Southern hemispheres (Harris et al., 2008).

Despite the wide use of van Heuklon's model in solar radiation models up to mid-90's (Kambezidis, 2012; Muneer et al., 1997; Kambezidis et al., 1998), its estimations are nowadays out of acceptable accuracy because average ozone levels declined during the 1980's \& 1990's over Europe. Therefore, its coefficients must be re-calculated.

Information derived from satellite measurements has been widely used in solar radiation models (NASA, 2011); however, there is still use for empirical ozone content models, for example in cases where satellite data are not available. The purpose of this study is to establish an empirical model for the ozone amount in the regions of Europe, based on satellite measurements accumulated over the past decades. Moreover, we explore possible interrelationships between the seasonal and geographical variation of ozone amount across the examined region. 


\section{DATA AND METHODOLOGY \\ Data}

NASA spacecrafts Nimbus-7 (1/11/1978-6/5/1993), Meteor-3 (22/8/1991-24/11/1994) and Earth Probe (25/7/1996-31/12/2005) have provided an extended database of daily total ozone column measurements over 206 locations worldwide, using the Total Ozone Mapping Spectrometer (TOMS)(NASA website).

Data provided by TOMS measurements has shown a depletion (NASA, 2011) in ozone layer since 1980. It is less in the equator area and increases with latitude toward the poles. In North Pole regions, it is a result of the late winter/spring ozone destruction that occurs there annually. The greatest declines, up to $30 \%$, are in the winter and spring, when the stratosphere is colder. Declines are about $3 \%$ below pre -1980 values for $35-60^{\circ} \mathrm{N}$, while in the tropics there are no significant trends. Northern minimum is observed during autumn (WMO, 2003; 2011). Recently, indication of an ozone partial recovery has been observed (ESA satellite measurements, 2013)

Complimentary with TOMS measurements, results of other studies are available. Some of the conclusions of these studies are (Bojkov and Bojkov et al., 1990; Brune et al., 1991; WMO, 2003; 2011):

- Northern mid-latitude winter and summer decreases during the 1980s were larger than the average trend since 1970 by about 2 per cent per decade, while significant longitudinal variance of the trend since 1979 is observed.

- The global-mean lower stratosphere cooled by $1-2^{\circ} \mathrm{K}$ and the upper stratosphere cooled by 4-6 ${ }^{\circ} \mathrm{K}$ from 1980 to about 1995 . The global-mean lower-stratospheric cooling did not occur linearly.

- Concerning ozone's vertical distribution, there is a decrease in the lower stratosphere at about 10 per cent/decade,

- In the upper stratosphere near $40 \mathrm{~km}$, changes are qualitatively consistent with theoretical predictions, but are smaller in magnitude. Measurements indicate that ozone levels in the troposphere have increased about 10 per cent per decade over the past two decades.

- Some physical factors also influence ozone amount. Major volcanic eruptions and solar activity have clear shorter-term effects.

For the needs of this analysis, TOMS measurements (version 8) from all three satellites were collected for 124 cities in Europe covering the period from 1/11/1978 until 31/12/2005 (NASA, 2011). The TOMS program has provided reliable measurements that have been submitted to quality control. Moreover, data has been checked for consistency and 20 irregular cases have been found. A lack of ozone recordings during the year has made these sites unreliable and they have been removed from the database. These mainly represent northern sites with latitudes over $70^{\circ} \mathrm{N}$. The final dataset under consideration included 104 cities (Annex, Table 1, Figure 2).

\section{Methodology}

In order to obtain an expression that better describes the ozone distribution across the entire Europe, a model based on van Heuklon's formula (eq. 1) was fitted to the European ozone data set, using non-linear regression analysis. In this analysis the parameters $\mathrm{J}$ and $\mathrm{H}$ were considered constant; $\mathrm{J}$ was taken as the average zone amount between $-5^{\circ},+5^{\circ}$ latitude from the satellite data of the years 1978-2005, equal to 260 D.U., and H retained its original value of 3 ,following some initial exploratory analyses.

The whole procedure included the following steps:

1. Firstly, in order to obtain the new model, a non-linear regression analysis based on equation (1) was performed on all available TOMS data for the European cities.

2. The second step was to perform exploratory nonlinear regression analyses, in order to examine the dependency of the model's parameters on latitude and longitude. Since the values of the parameters derived initially were not representative of van Heuklon's model, constrained regression analysis was deemed necessary,so initial constraints had to be established.

3. To determine the constraints, we performed a set of nonlinear regression analyses to examine the behavior of each one specific parameter for the different cities, when the other parameters remained constant.

4. This set of calculations resulted in city specific parameter values. A basic check was performed, and the minimum and maximum of the obtained values were established as constrains for the next step. 
5. Next, step 2 was repeated. However, for some parameters the obtained values were equal to the corresponding constraints indicating that the limits were too restrictive. This step was repeated with gradually relaxing limits until we retrieved a final set of parameter values, not concentrated in the corresponding limits.

6. From these values a final set of constraints was derived and the new model was fitted, including all data.

7. To evaluate the robustness of the new model, an uncertainty and sensitivity analysis has been performed. For this reason, two statistic parameters have been used: the systematic error (bias) and the root mean squared error (RMSE\%). Both models: the original van Heuklon model and the new model, were evaluated against TOMS data.

\section{RESULTS}

The parameter estimates from the non-linear regression analysis of step 1 (standard errors in parentheses) are:

$$
\begin{aligned}
& \mathrm{O}_{3}=260.0(0.1)+\{80.0(0.2)+56.3(0.1) \cdot \sin [0.9865 \cdot(\mathrm{E}-17.3(0.1)]-14.0(0.2) \cdot \sin [(3 \cdot(\lambda+67.3(0.3))]\} \\
& \quad\left[\sin ^{2}(-201.7(0.001) \cdot \varphi)\right]
\end{aligned}
$$

The new model of step 6 has normal values and a better approximation to the real TOMS data. The values of the parameters for this new model are: $J=260.0(0.3), C=48.91(0.06), F=-17.85(0.07)$, $G=-1.44(0.08), I=51.2(1.5), \beta=1.497(0.001), A=76.3(0.4)$.

Having in mind the calculated values, the equation (4) is the new adjusted van Heuklon Model for the Europe area, based on the TOMS data:

$$
\begin{gathered}
\mathrm{O}_{3}=260.0(0.3)+\{76.3(0.4)+48.91(0.06) \cdot \sin [0.9865 \cdot(\mathrm{E}-17.85(0.07)]- \\
1.44(0.08) \cdot \sin [(3 \cdot(\lambda+51.2(1.5))]\} \cdot\left[\sin ^{2}(1.497(0.001) \cdot \varphi)\right]
\end{gathered}
$$

Fitting the van Heuklon model to the measured European daily ozone amounts provided a rather low coefficient of determination $\left(R^{2}=0.28\right)$ that was improved through the followed procedure into $R^{2}=$ 0.45 . This result might be considered at least as moderate especially if one takes into account that day-to-day variation may be more than $30 \%$ especially during the cold period and keeping in mind that the fitting refers to a 30 -year period of TOMS measurements. This moderate fit also suggests that even though the model is a fairly good representation of the total ozone amount dependencies, there might be other relationships that remain hidden in the model's parameters.

In order to examine the robustness of the new model, an uncertainty analysis has been made, followed by a sensitivity analysis. Two statistic parameters have been used for the uncertainty analysis: the systematic error (bias) and the root mean squared error (RMSE\%). The systematic error quantifies the over/underestimation between ozone quantities of the model and the TOMS ozone quantities. The root-mean-square error (RMSE) is a measure of the differences between ozone quantities of the model and the ozone quantities actually observed by TOMS.

The final model presents less over/underestimation of the measured ozone as the systematic error is only $0-0.1 \%$ compared to $10.9 \%$ of the original van Heuklon's model. The final model also presents a better approximation of the real ozone quantities since the root mean squared error (RMSE\%) is about $10.6 \%$ compared to $16.5 \%$ of the original van Heuklon's model. Figure 1 presents the results of the new model compared to the original van Heuklon's model for the TOMS dataset.

The sensitivity analysis has been performed through the examination of the average ozone amount, taking under consideration the variance of the new model's parameters for the total European sites (Table 1). In this way, it is possible to identify the effect of each parameter on the uncertainty of the model, regarding the estimation of ozone quantities.

The results of the analysis showed that the parameters regarding the longitude, $A$ and $\beta$, contribute to the result's uncertainty more than the others. Specifically, the variation of parameter $A$ alone, which is related to the effect of the longitude, may modify the result by $161 \%$. Also, the variation of parameter $\beta$, which represents the latitude of the maximum ozone, can modify the result by $48 \%$. The rest of the parameters do not contribute decisively to the result's uncertainty. The results of the estimated values of parameters for each location are presented in Annex, Table 1. The estimated values of the final model's parameters are shown at Figure 2. 
A comparison of the original van Heuklon's model (eq. 2) with these adjusted to European data (eq. $3,4)$, reveals some differences in the parameters' values caused by the restricted extent of the examined region. Specifically, the latitudinal amplitude constant $(A)$ in the final model is about half of the original value.

Furthermore, $\mathrm{A}$ is a constant relevant to the latitudinal amplitude and not an ozone amount. The dominant values for parameter $A$ are found between $60-130$, while the value that represents better the European area is 76.3 , recommended by equivalent (4).

The amplitude of the seasonal variation (parameter $\mathrm{C}$ ) obtains values that are in general agreement with the value given by van Heuklon's model (40). The majority of these values range between 35 and -50 , and the European value is -48.91 . This shows a seasonal variation about 100 D.U. that represents most of the European area, apart from few northern sites where seasonal variation has higher levels.

Parameter $\mathrm{F}$ represents the delay of the appearance of the maximum and minimum ozone values in relation to the $90^{\text {th }}$ and $270^{\text {th }}$ day of the year respectively. Considering the European area, the difference in $\mathrm{F}$ suggests that the ozone maximum happens somewhat earlier in the year. The recommended value for Europe is 17.85, though the maximum value tends to occur later in the eastern areas.

Parameter $G$ is relevant to the effect of the longitudinal variation and its value in the model is taken as constant (1.44), though in van Heuklon's model is 20. This indicates that the effect of the longitudinal variation in the observed ozone amount is less than initially considered for Europe.

The correction parameter for the effect of the longitude is I, which in the original van Heuklon's model was estimated at 20, referring to the European area in total, while in the new model for Europe its value is 51.2 . The new value of I moves the location of its maximum westwards, about in $\lambda=20^{\circ}$, in agreement with TOMS observations.

Parameter $\beta$ has the value 1.497 in the new model, on the contrary of van Heuklon model's value, which is 1.28. This indicates that for Europe the maximum amounts of ozone are found in latitudes lower than $70^{\circ}$, mostly about $60^{\circ}$. Finally, the fact that $\mathrm{J}$ parameter is the equatorial ozone amount taken at 260 (according to the most recent satellite measurements) and not at 235 as in van Heuklon's model, has to be emphasized.

Moreover, some other interesting relationships between the city specific estimates of the model parameters and latitude and longitude emerged. The cross-correlation results between the model parameters are given in Annex, Table 2. From these results we can notice that $F$ is related to longitude, there is a linear correlation between $A$ and $G$.

There is also an exponential relationship between $C$ and $\beta$. The strong correlation between $A$ and $G$ $(R=-0.912)$ means that in the case of large latitude variation $A$ (e.g. in the northern latitudes), the longitudinal variation $G$ decreases. The correlation of $C$ and $\beta(R=-0.511)$ suggests that as the $C$ increases (e.g. in the northern latitudes), $\beta$ decreases. 

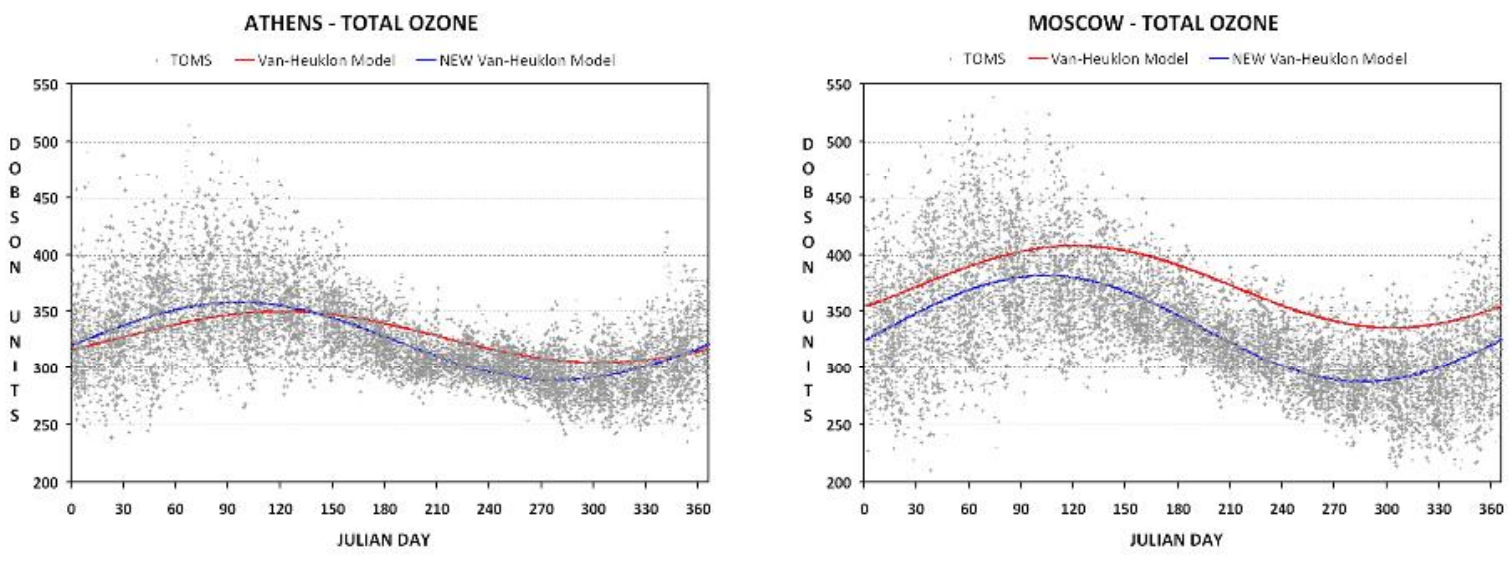

OSLO - TOTAL OZONE

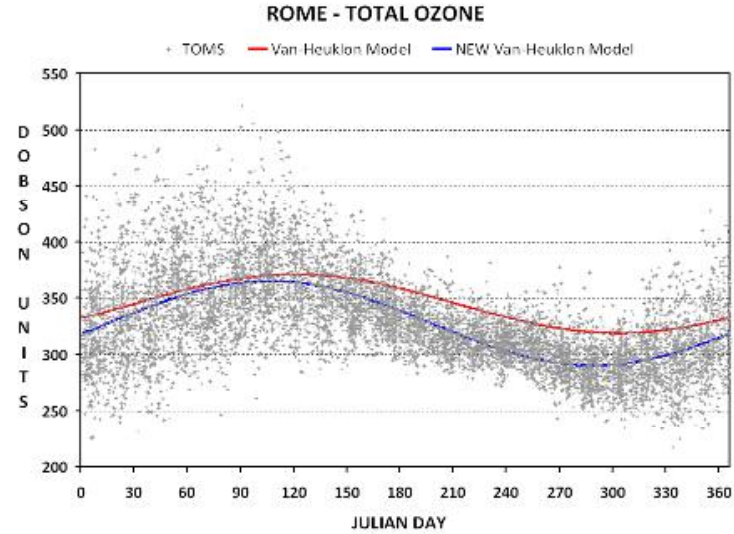

TOMS - van-Heuklon Model -NEW van-Heuklon Model

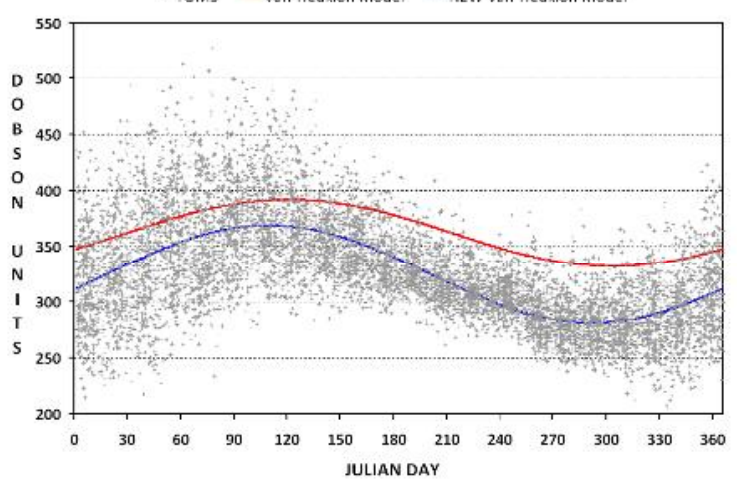

COLIMBARI - TOTAL OZONE

TOMS - Van-Heuklon Model - NeW Van-Heuklon Modr

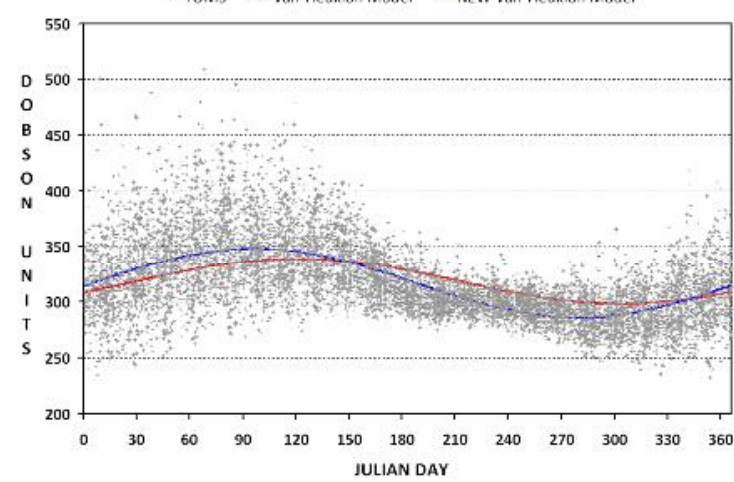

Figure 1. The temporal variation of ozone amount for six chosen cities (Athens, Moscow, Oslo,

Rome, Arosa, Kolimbari) and the calculated values from the new model (eq. 4). The new model (blue line) adjusts much better than the original van Heuklon's model (red line) to the average values of TOMS's measurements (gray points)

\section{CONCLUSIONS}

Utilizing the large amount of data made available from the TOMS instruments aboard three satellites, we attempted to adjust the model proposed by van Heuklon for the calculation of total atmospheric ozone, over the European area. The resulting model fits the satellite data rather well, whereas the differences observed between the new estimates of the model parameters and their original values were representative of the European area considered in our study. In this frame, the new model could be a useful tool for the modeling of ozone in Europe area.

Furthermore it was shown that the phase and amplitude parameters of the seasonal component of the fitted van Heuklon model have significant dependence on latitude and longitude. This indicates that, though successful, van Heuklon's model might be ignoring some important modes of the total ozone variation, suggesting that, for specific regions, other mathematical models might be worth exploring. 

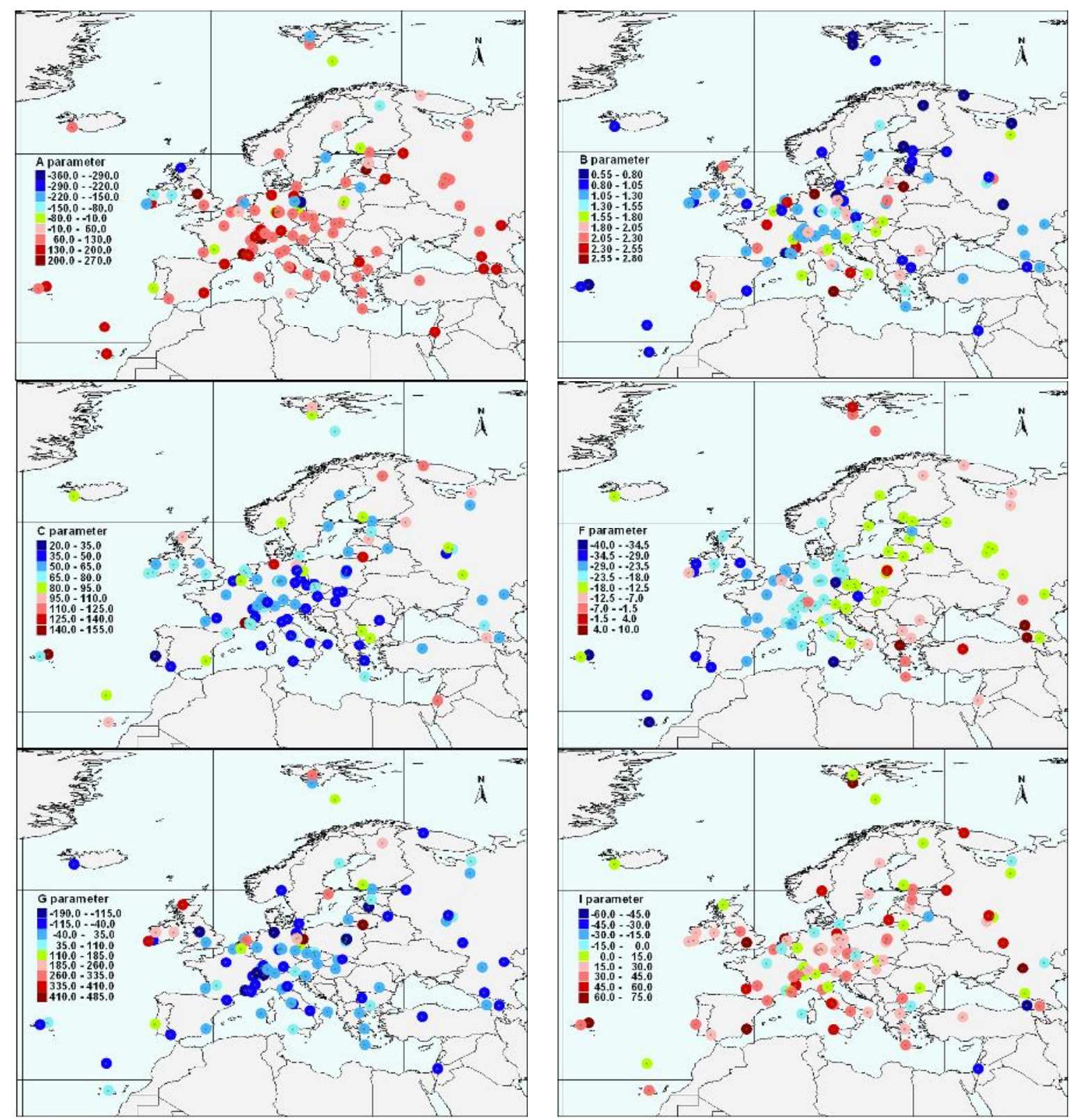

Figure 2. Spatial variation of model parameters A, b, C, F, G and I across Europe. Values are presented in Annex, Table 1

\section{ACKNOWLEDGEMENTS}

The present study was conducted under traineeship and funded by the University of Athens grant traineeships program.

\section{REFERENCES}

Bird R.E. and Hulstrom R.L. (1981) A simplified clear sky model for direct and diffuse insolation on horizontal surfaces. Solar Energy Research Institute, Golden, Colorado.

Bojkov R., Bishop L., Hill W.J., Reinsel G.C. and Tiao G.C. (1990) A statistical trend analysis of revised Dobson total ozone data over the Northern Hemisphere, J. Geophys. Res., 95, 9785-807.

Brune W.H., Anderson J.G., Toohey D.W., Fahey D.W., Kawa S.R., Jones R.L., McKenna D.S. and Poole L.R. (1991) The potential for ozone depletion in the Arctic polar stratosphere, Science, 252, 126066 . 
Eichmann K.-U., Weber M., Bramstedt K. and Burrows J.P (2002).,Ozone depletion in Northern Hemisphere winter/spring 1999/2000 as measured by the Global Ozone Monitoring Experiment on ERS2.

European Space Agency (ESA) http://www.esa.int/Our_Activities/ Observing_ the_Earth/ls_the_ozone_layer_on_the_road_to_recovery), (Accessed 5/2013).

Fioletov V.E., Kerr J.B., McElroy C.T.', Wardle D.I., Savastiouk V. and Grajnar T.S. (2005). The Brewer reference triad, Geophysical Research Letters, 32, L2085, 4 p.

Fioletov V.E. (2009) Estimating the 27-day and 11-year solar cycle variations in tropical upper stratospheric ozone, Journal of Geophysical Research,114, D02302.

Harris N.R.P., Kyrö E., Staehelin J., Brunner D., Andersen S.-B., Godin-Beekmann S., Dhomse S., Hadjinicolaou P., Hansen G., Isaksen I., Jrrar A., Kapetchko A., Kivi R., Knudsen B., Krizan P., Lastovicka J., Maeder J., Orsolini Y., Pyle J.A., Rex M., Vanicek K., Weber M., Wohltmann I., Zanis P. and Zerefos C. (2008): Ozone trends at northern mid- and high latitudes - a European perspective, Annales. Geophysicae, 26, 1207-1220.

Hoyt D.V. (1978) A model for the calculation of solar global insolation, Solar Energy, 21, 7-35.

Kambezidis H.D., Katevatis E.M.,Petrakis M., Lykoudi S. and Asimakopoulos D.N. (1998) Estimation of the Linke and Unsworth-Monteith turbidity factors in the visible spectrum: application for Athens, Greece, Solar Energy, 62(1), 39-50.

Kambezidis H.D. (2012) 3.02-The Solar Resource, In: Comprehensive Renewable Energy, Volume 3: Solar Thermal Systems: Components and Applications, Elsevier, p.p. 27-84

Lacis A.L. and Hansen J.E. (1974) A parameterization for the absorption of solar radiation in the Earth's atmosphere, J. Atmos. Sci., 31, 118-133.

Muneer T., Gueymard C., Kambezidis H. (1997) ,Solar Radiation and Daylight Models, Elsevier

NASA (2011) Earth Probe TOMS Data \& Images http://toms.gsfc.nasa.gov/eptoms/ep_v8.html. (Accessed 06/2011). NASA-Space-Based Measurements of Ozone and Air Quality (http://ozoneaq.gsfc.nasa.gov/)

Psiloglou B.E., Santamouris M., Varotsos C. and Asimakopoulos D.N. (1996) A new parameterization of the integral ozone transmission, Solar Energy, 56, 573-581.

Van Heuklon T.K. (1979) Estimating atmospheric ozone for solar radiation models, Solar Energy, 22, 6368.

Ray E.A., Moore F.L., Rosenlof K.H., Davis S.M., Boenisch H., Morgenstern O., Smale D., Rozanov E., Hegglin M., Pitari G., Mancini E., Braesicke P., Butchart N., Hardiman S., Li F., Shibata K. and Plummer D.A. (2010) Evidence for changes in stratospheric transport and mixing over the past three decades based on multiple data sets and tropical leaky pipe analysis, Journal of Geophysical Research,115, D21.

WMO (World Meteorological Organization) (2003) Scientific Assessment of Ozone Depletion: 2002, Global Ozone Research and Monitoring Project-Report No. 47, 498 pp., Geneva, 2003.

WMO (World Meteorological Organization) (2011) Scientific Assessment of Ozone Depletion: 2010, Global Ozone Research and Monitoring Project-Report No. 52, 516 pp., Geneva, Switzerland, 2011.

\section{ANNEX}

Table 1. Coordinates of the 104 cities selected across the European area along with the estimated values A, C, F, G, I and $\beta$. The parameters' values have been calculated for each site by non-linear regression analysis of satellite data

\begin{tabular}{|l|c|r|r|r|r|r|r|c|}
\hline LOCATION & $\boldsymbol{\varphi}$ & \multicolumn{1}{c|}{$\boldsymbol{\lambda}$} & \multicolumn{1}{c|}{ A } & \multicolumn{1}{c|}{ C } & \multicolumn{1}{c|}{$\mathbf{F}$} & \multicolumn{1}{c|}{$\mathbf{G}$} & \multicolumn{1}{c|}{$\mathbf{I}$} & \multicolumn{1}{c|}{ b } \\
\hline Abastumani & 41.76 & 42.92 & 148.27 & 106.16 & 8.63 & -24.65 & -49.52 & 0.92 \\
\hline Amsterdam & 52.37 & 4.89 & 93.69 & 65.91 & -25.73 & -10.80 & 67.22 & 1.10 \\
\hline Ankara & 39.94 & 32.83 & 116.63 & 64.99 & 3.69 & -99.27 & 25.29 & 1.25 \\
\hline Arkhangelsk & 64.46 & 40.47 & 81.89 & 107.39 & -10.54 & 52.46 & -12.94 & 0.70 \\
\hline Arkona & 54.67 & 13.43 & 127.75 & 69.02 & -19.73 & -48.83 & -3.82 & 1.03 \\
\hline Arosa & 46.77 & 9.68 & 105.63 & 62.90 & -18.35 & -21.63 & 1.91 & 1.21 \\
\hline
\end{tabular}


Table 1 (continued). Coordinates of the 104 cities selected across the European area along with the estimated values $A, C, F, G, I$ and $\beta$. The parameters' values have been calculated for each site by non-linear regression analysis of satellite data

\begin{tabular}{|c|c|c|c|c|c|c|c|c|}
\hline LOCATION & $\varphi$ & $\lambda$ & A & C & $\mathbf{F}$ & G & I & b \\
\hline Athens & 37.99 & 23.77 & 92.10 & 47.14 & -5.43 & -9.00 & 25.01 & 1.55 \\
\hline Basel & 47.60 & 7.60 & 95.03 & 57.52 & -21.25 & -7.09 & -0.70 & 1.25 \\
\hline Bearlsland & 74.32 & 19.09 & -63.34 & 68.54 & -5.45 & 145.36 & 12.14 & 0.97 \\
\hline Belsk & 51.84 & 20.79 & 13.13 & 62.37 & -13.27 & 100.37 & 18.93 & 1.11 \\
\hline Berlin & 52.26 & 12.95 & 205.94 & 99.51 & -20.24 & -141.01 & 40.22 & 0.77 \\
\hline Biscarrosse & 44.38 & 0.89 & 96.90 & 64.26 & -28.30 & 12.92 & 46.76 & 1.17 \\
\hline Bordeaux & 44.84 & 0.58 & -37.00 & 40.64 & -25.86 & 104.91 & 30.82 & 2.13 \\
\hline Briancon & 44.91 & 6.65 & 77.66 & 38.52 & -19.14 & -46.22 & 47.27 & 2.37 \\
\hline Brindisi & 40.66 & 17.95 & 60.09 & 40.79 & -12.16 & 25.64 & 29.14 & 1.73 \\
\hline Bucharest & 44.48 & 26.13 & 87.81 & 40.80 & -8.55 & -12.98 & 6.98 & 1.89 \\
\hline Budapest & 47.43 & 19.18 & 97.17 & 43.76 & -14.44 & -29.71 & 25.65 & 1.67 \\
\hline Caheriveen & 52.12 & -9.50 & 144.97 & 72.36 & -31.94 & -97.94 & 16.33 & 1.01 \\
\hline Carpentras & 44.09 & 5.05 & 249.93 & 142.07 & -21.79 & -163.37 & -3.50 & 0.71 \\
\hline Chopak & 48.93 & 19.58 & 60.23 & 44.72 & -14.65 & 13.42 & 2.81 & 1.95 \\
\hline Cimljansk & 47.73 & 42.25 & 86.76 & 64.97 & 1.50 & -38.95 & 63.63 & 1.14 \\
\hline Colonge & 50.93 & 6.92 & 114.11 & 60.17 & -23.94 & -37.41 & 4.27 & 1.19 \\
\hline De Bilt & 52.03 & 5.18 & -213.25 & 66.52 & -26.79 & 320.72 & 21.45 & 2.46 \\
\hline Dresden & 51.12 & 13.68 & -56.16 & 45.80 & -19.37 & 130.94 & 19.15 & 1.90 \\
\hline Drichtelberg & 50.43 & 12.94 & -126.49 & 65.08 & -19.22 & 230.71 & 17.92 & 1.10 \\
\hline Dublin & 53.34 & -6.26 & 116.14 & 47.63 & -30.39 & -66.74 & 20.13 & 1.86 \\
\hline Duchal Madeira & 32.61 & -16.89 & 81.60 & 44.21 & -36.66 & 4.37 & 21.75 & 1.51 \\
\hline El Arenosillo & 37.11 & -6.73 & 158.35 & 80.75 & -30.91 & -86.38 & 8.53 & 1.01 \\
\hline Geneva & 46.21 & 6.17 & 104.26 & 42.22 & -21.11 & -51.49 & 38.96 & 1.75 \\
\hline Hamburg & 53.34 & 9.61 & 174.26 & 129.75 & -22.52 & -141.86 & -12.84 & 2.68 \\
\hline Haute Provence & 43.94 & 5.72 & 157.16 & 73.77 & -21.08 & -74.82 & 3.60 & 1.05 \\
\hline Helsinki & 60.12 & 24.95 & 82.08 & 64.27 & -15.18 & -30.48 & 41.18 & 1.03 \\
\hline Hohenpeissenberg & 47.80 & 11.02 & 178.61 & 64.10 & -21.12 & -102.08 & 32.77 & 1.14 \\
\hline Hornsund & 76.89 & 15.55 & 96.48 & 86.60 & -2.07 & -2.26 & 67.43 & 0.78 \\
\hline Hradec & 50.18 & 15.83 & 9.29 & 47.87 & -16.05 & 74.19 & 21.31 & 1.50 \\
\hline Inselsberg & 50.85 & 10.46 & 121.76 & 69.76 & -20.88 & -27.83 & 40.82 & 1.05 \\
\hline Izana Tenerife & 28.31 & -16.50 & 137.19 & 96.05 & -36.19 & 43.77 & 39.61 & 0.94 \\
\hline Jerusalem & 31.79 & 35.22 & 176.31 & 119.66 & -7.32 & -76.25 & -42.00 & 0.80 \\
\hline Jokioinen & 60.72 & 23.49 & -26.30 & 92.74 & -14.77 & 158.71 & 6.10 & 0.79 \\
\hline JungDraujoch & 46.55 & 7.98 & 200.14 & 68.35 & -19.77 & -115.18 & 11.29 & 1.13 \\
\hline Kaltennordheim & 50.63 & 10.15 & -13.21 & 57.01 & -20.82 & 109.98 & 26.37 & 1.23 \\
\hline Kaunas & 54.54 & 23.57 & -215.05 & 127.24 & -14.17 & 443.12 & 13.24 & 2.61 \\
\hline Kislovodsk & 43.74 & 42.66 & 175.67 & 73.41 & 4.61 & -93.21 & 4.03 & 1.10 \\
\hline Kolimbari Crete & 35.53 & 23.90 & 125.13 & 67.77 & -5.30 & -8.99 & 35.16 & 1.20 \\
\hline Legionowo & 52.40 & 20.99 & 50.61 & 62.81 & -17.94 & 56.86 & 17.44 & 1.11 \\
\hline Lille & 50.65 & 3.09 & 83.62 & 42.35 & -25.77 & -26.21 & 42.75 & 1.71 \\
\hline Lindenberg & 52.22 & 14.11 & -347.25 & 80.96 & -19.21 & 476.48 & 16.59 & 0.93 \\
\hline
\end{tabular}


Table 1 (continued). Coordinates of the 104 cities selected across the European area along with the estimated values A, C, F, G, I and $\beta$. The parameters' values have been calculated for each site by non-linear regression analysis of satellite data

\begin{tabular}{|c|c|c|c|c|c|c|c|c|}
\hline LOCATION & $\varphi$ & $\lambda$ & A & C & $\mathbf{F}$ & G & I & b \\
\hline Lisbon & 38.78 & -9.13 & -51.47 & 32.91 & -34.17 & 111.49 & 35.82 & 2.33 \\
\hline Longyear & 78.11 & 15.58 & -150.83 & 105.29 & 2.20 & 267.32 & 13.85 & 0.68 \\
\hline MaceHead & 53.27 & -9.11 & -115.77 & 58.00 & -31.88 & 254.73 & 26.94 & 1.18 \\
\hline $\begin{array}{l}\text { MagnyLes } \\
\text { Hameaus }\end{array}$ & 48.72 & 2.07 & 166.57 & 50.08 & -25.85 & -96.48 & 36.17 & 1.42 \\
\hline Manchester & 53.46 & -2.15 & 250.37 & 64.33 & -29.49 & -180.64 & 42.79 & 1.10 \\
\hline Meiningen & 50.57 & 10.38 & 137.81 & 71.92 & -20.59 & -49.76 & 40.09 & 1.03 \\
\hline Minsk & 55.83 & 27.47 & 146.61 & 57.09 & -12.65 & -106.20 & -15.46 & 1.19 \\
\hline MontLouis & 42.51 & 2.14 & 195.51 & 73.72 & -24.35 & -102.34 & 42.41 & 1.06 \\
\hline Moscow & 55.76 & 37.55 & 62.60 & 75.00 & -12.76 & 70.42 & 4.39 & 2.29 \\
\hline Mount Krvavec & 46.30 & 14.52 & 70.81 & 42.40 & -16.95 & 8.88 & 42.85 & 1.71 \\
\hline Murcia & 38.01 & -1.18 & 139.90 & 81.01 & -24.27 & -16.55 & 75.49 & 0.99 \\
\hline Murmansk & 68.86 & 33.04 & 38.99 & 111.18 & -8.15 & -102.50 & 52.25 & 0.66 \\
\hline Naples & 40.86 & 15.18 & 111.06 & 38.39 & -12.82 & -97.13 & 36.45 & 2.52 \\
\hline Neuglobsow & 52.99 & 12.61 & 174.90 & 106.07 & -19.83 & -97.40 & 45.45 & 0.78 \\
\hline Obninsk & 55.12 & 36.57 & 78.75 & 48.44 & -12.52 & -3.80 & 21.73 & 1.41 \\
\hline Oslo & 59.87 & 10.70 & 103.49 & 93.08 & -20.12 & -48.47 & 58.94 & 0.80 \\
\hline Oxford & 51.75 & -1.19 & 106.00 & 70.99 & -28.51 & -10.32 & 62.09 & 1.05 \\
\hline Paris ValJoyeaux & 48.51 & 2.05 & 74.75 & 58.40 & -25.76 & -40.88 & -10.37 & 2.48 \\
\hline Payerne & 46.82 & 6.95 & 198.94 & 62.69 & -20.84 & -117.64 & 33.95 & 1.17 \\
\hline Penhas Douradas & 40.43 & 7.55 & 85.87 & 42.03 & -23.33 & 27.08 & -8.89 & 1.60 \\
\hline Plesetsk & 62.51 & 40.34 & 78.62 & 58.37 & -12.15 & 7.12 & 13.86 & 1.76 \\
\hline Poprad Ganovce & 49.03 & 20.32 & 127.62 & 45.53 & -14.78 & -68.35 & 22.43 & 1.64 \\
\hline Potsdam & 52.37 & 13.08 & -162.05 & 48.56 & -19.92 & 239.52 & 18.59 & 1.98 \\
\hline Praha & 50.00 & 14.65 & 77.03 & 44.05 & -17.82 & -12.54 & 37.41 & 1.82 \\
\hline Preila & 55.32 & 21.21 & 71.65 & 50.57 & -15.49 & -14.08 & 47.01 & 1.85 \\
\hline Reykjavik & 63.98 & -21.91 & 64.64 & 82.78 & -14.08 & -87.70 & 5.42 & 0.81 \\
\hline Riga & 57.29 & 24.38 & 208.87 & 101.82 & -15.88 & -162.23 & 28.76 & 0.77 \\
\hline Rojen & 41.72 & 24.73 & 100.16 & 84.92 & -8.09 & 65.98 & -7.91 & 1.01 \\
\hline Rome & 41.88 & 12.48 & 177.85 & 70.64 & -15.40 & -75.50 & 34.08 & 1.11 \\
\hline SantaMariaAzores & 38.84 & -25.92 & 196.53 & 150.93 & -38.75 & 88.56 & 75.83 & 0.72 \\
\hline Schauinsland & 47.92 & 7.92 & 162.06 & 61.15 & -21.67 & -85.47 & 8.54 & 1.19 \\
\hline Schmuek & 50.65 & 10.77 & 67.72 & 53.21 & -20.70 & 16.25 & 19.77 & 1.31 \\
\hline Sestola & 44.22 & 10.77 & 80.17 & 39.32 & -17.85 & -33.72 & 42.34 & 2.01 \\
\hline Sodankyla & 67.25 & 26.64 & -99.54 & 115.05 & -10.63 & 247.05 & 2.97 & 0.64 \\
\hline Sofia & 42.81 & 23.38 & 137.95 & 81.69 & -10.00 & -52.23 & 39.81 & 1.02 \\
\hline Sonnblick & 47.05 & 12.94 & 149.68 & 98.20 & -16.47 & -61.34 & 47.02 & 0.88 \\
\hline S PietroCapofume & 44.66 & 11.62 & -165.81 & 56.64 & -17.01 & 269.31 & 17.21 & 1.26 \\
\hline Stockholm & 59.31 & 18.03 & -266.04 & 96.76 & -19.10 & 400.84 & 13.14 & 2.25 \\
\hline $\begin{array}{l}\text { StPetersburg } \\
\text { Voeidovo }\end{array}$ & 59.91 & 30.27 & 82.86 & 76.03 & -14.10 & 28.98 & -7.89 & 0.90 \\
\hline StrathVaich & 56.17 & -6.60 & 1.25 & 68.29 & -27.87 & 102.86 & 39.95 & 1.01 \\
\hline
\end{tabular}


Table 1 (continued). Coordinates of the 104 cities selected across the European area along with the estimated values A, C, F, G, I and $\beta$. The parameters' values have been calculated for each site by non-linear regression analysis of satellite data

\begin{tabular}{|c|c|c|c|c|c|c|c|c|}
\hline LOCATION & $\varphi$ & $\lambda$ & A & C & $\mathbf{F}$ & G & 1 & b \\
\hline Svratouch & 49.73 & 16.03 & 142.04 & 60.84 & -16.77 & -65.35 & 30.59 & 1.17 \\
\hline Tahkuse & 58.49 & 24.91 & 84.50 & 75.73 & -15.88 & -42.93 & 42.47 & 0.95 \\
\hline Tbilisi & 41.69 & 44.95 & 65.83 & 40.33 & 8.63 & 23.96 & 18.44 & 2.00 \\
\hline Terceicalsland & 38.65 & -27.22 & -9.95 & 36.04 & -39.58 & 67.82 & 59.02 & 2.77 \\
\hline Thessaloniki & 40.51 & 22.97 & 18.57 & 91.83 & -8.64 & 178.93 & -3.28 & 0.97 \\
\hline Trapani & 37.92 & 12.50 & -206.59 & 65.54 & -11.98 & 335.40 & 19.34 & 1.16 \\
\hline Uccle Brussels & 50.80 & 4.35 & 172.72 & 72.02 & -24.89 & -105.02 & 43.58 & 1.06 \\
\hline Valencial. & 51.93 & -10.25 & 87.75 & 48.35 & -32.13 & -18.33 & 25.11 & 1.44 \\
\hline Valensole & 43.83 & 21.22 & 64.62 & 39.24 & -21.53 & 5.39 & 46.24 & 1.90 \\
\hline Vienna & 48.20 & 16.37 & 50.68 & 50.36 & -15.81 & 39.07 & 23.66 & 1.54 \\
\hline Vigna Di Valle & 42.09 & 12.24 & 151.74 & 63.01 & -15.60 & -66.75 & -1.06 & 1.19 \\
\hline Vindelin & 64.09 & 19.75 & 77.45 & 89.76 & -15.56 & -53.01 & 57.64 & 0.77 \\
\hline Volgograd & 48.59 & 45.63 & -57.53 & 49.73 & 3.00 & -171.76 & 33.33 & 2.28 \\
\hline Voronez & 51.70 & 39.16 & 65.09 & 45.31 & -5.90 & -38.03 & 27.61 & 1.87 \\
\hline Warsaw & 52.24 & 21.00 & 113.27 & 85.08 & -13.28 & -40.85 & 52.38 & 0.87 \\
\hline Zurich & 47.36 & 8.52 & 128.50 & 43.57 & -20.35 & -69.77 & 10.31 & 1.70 \\
\hline Zvenigorod & 55.68 & 36.77 & 84.41 & 54.62 & -13.22 & 43.39 & 19.56 & 1.17 \\
\hline
\end{tabular}

Table 2. Correlations of the parameters of the final model with latitude and longitude. It is obvious that there is an important correlation between parameter $F$ and longitude $\left(R^{2}=0.859\right)$, which indicates that the maximum values tend to appear earlier in the year while moving to the east. Also, of high importance is the reverse correlation between $A$ and $G(-0.912)$, which shows a negative relationship between them. On the contrary, there are no satisfactory correlations between the rest of the parameters

Correlation Matrix (R)

\begin{tabular}{lcccccccc}
\hline & LAT & LON & A & C & F & G & I & b \\
\hline LAT & 1,000 & 0,226 & $-0,251$ & 0,228 & 0,211 & 0,156 & 0,035 & $-0,225$ \\
\hline LON & 0,226 & 1,000 & $-0,059$ & 0,054 & 0,859 & $-0,011$ & $-0,295$ & $-0,031$ \\
\hline A & $-0,251$ & $-0,059$ & 1,000 & 0,088 & $-0,072$ & $-0,912$ & 0,076 & $-0,285$ \\
\hline C & 0,228 & 0,054 & 0,088 & 1,000 & 0,091 & 0,072 & $-0,127$ & $-0,511$ \\
\hline F & 0,211 & 0,859 & $-0,072$ & 0,091 & 1,000 & $-0,013$ & $-0,277$ & $-0,117$ \\
\hline G & 0,156 & $-0,011$ & $-0,912$ & 0,072 & $-0,013$ & 1,000 & $-0,116$ & 0,149 \\
\hline I & 0,035 & $-0,295$ & 0,076 & $-0,127$ & $-0,277$ & $-0,116$ & 1,000 & $-0,027$ \\
\hline b & $-0,225$ & $-0,031$ & $-0,285$ & $-0,511$ & $-0,117$ & 0,149 & $-0,027$ & 1,000 \\
\hline
\end{tabular}

